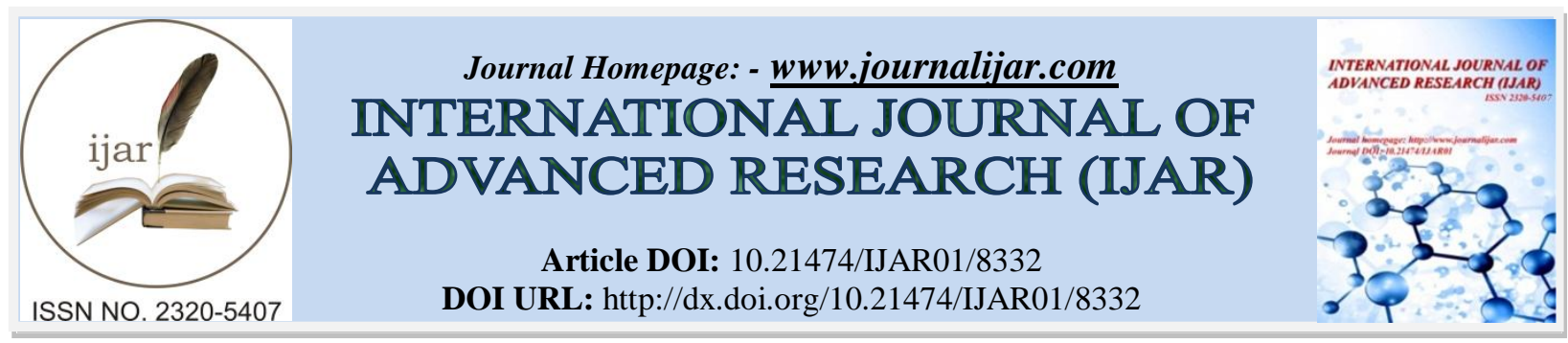

RESEARCH ARTICLE

\title{
AQUACULTURE POTENTIAL, STATUS, CONSTRAINTS AND FUTURE PROSPECTS IN ETHIOPIA: A REVIEW.
}

Gadisa Natea.

Department of Biology, College of Natural Sciences, Jimma University, Jimma, Ethiopia.

\section{Manuscript Info}

Manuscript History

Received: 08 November 2018

Final Accepted: 10 December 2018

Published: January 2019

Key words:-

Aquaculture, Constraints, Fish, Food, Potential, Water bodies.

\section{Abstract}

This review was focus on the Ethiopian aquaculture circumstances. Its aim was to assess aquaculture potential, status, constraints and future prospects in Ethiopia. Aquaculture not only in Ethiopia but also in many countries of the world can plays a great role in providing additional food and employment for the rising world population. Moreover in developing countries like Ethiopia it plays a lion share in food supply and poverty alleviation strategy. Beyond this it can serve as one of the best alternatives mitigation mechanism of the overexploited natural aquatic resources. In Ethiopia, eventhough there was enormous potential for aquaculture production, it remains more potential than actual practice. Currently, there was no this much plentiful production of aquaculture in this country i.e. the country Ethiopia didn't benefited from this sector. For the insignificant production of aquaculture in Ethiopia there were a number of challenges which contribute for this records. But there are different proposed preconditions by the government of Ethiopia to improve the fishery products by aquaculture supplements. Generally since aquaculture can play a great role for the development of the country Ethiopia, the government must give attention and form suitable environment for adequate production from aquaculture.

Copy Right, IJAR, 2018,. All rights reserved.

\section{Introduction:-}

Aquaculture is defined by the UN's Food and Agriculture Organization (FAO) as the 'farming of aquatic organisms including fish, molluscs, crustaceans and aquatic plants'. Farming implies some sort of intervention in the rearing process to enhance production, such as regular stocking, feeding, protection from predators and it can also includes encouraging of accessible market chain. This farming can be ran by individual or corporate ownership for planning of stock being cultivated, sites selection, development and operation of aquaculture systems, providing of facilities and practices, the production and transporting of the products ( FAO, 1996).

Aquaculture is one of the oldest food production activities in the history of mankind (FAO, 2002). It is the fastest growing food producing sector in the world (FAO, 2006; AFD, COM and GIZ, 2017). Eventhough Global aquaculture production grow faster than other major food production sectors, it no longer enjoys the high annual growth rates of the $1980 \mathrm{~s}$ and $1990 \mathrm{~s}$ (11.3 and 10.0 percent, excluding aquatic plants). Average annual growth 
declined to 5.8 percent during the period 2000-2016, although double-digit growth still occurred in a small number of individual countries, particularly in Africa (FAO, 2018). It is probably one of the most promising answers by providing additional food and employment for the rising world population if it will amplified. FAO (2005) reported that out of the total tonnes of fish consumed in the world every year, almost half is produced in a controlled environment, whereas the remaining half is harvested from the wild (Lakew et al., 2016). Aquaculture can serve as one of the best alternatives for the over-exploited natural aquatic resources, i.e. aquaculture can help to reduce pressure and maintain the ecological balance of the natural ecosystem (Lakew et al., 2016).

Aquaculture is developing, expanding and intensifying in almost all regions of the world, except in Sub-Saharan Africa, as the global population demand for aquatic food products is expected to increase (FAO, 2012). As the report of World Bank (2013) projected indicates per capita fish consumption in Sub-Saharan Africa is decline at an annual rate of 1 percent to 5.6 kilograms during the 2010-30 period. But, due to rapid population growth, which is estimated at 2.3 percent annually during the $2010-30$ periods, the total fish food consumption demand would grow substantially (by 30 percent between 2010 and 2030).

World Bank (2013) projected report indicated that in-line with rapid population growth, capture fish production is to increase from an average of 5,422 thousand tons in 2007-09 to 5,472 thousand tons in 2030. Moreover, aquaculture is projected to increase from 231 thousand tons to 464 thousand tons during the same period in Sub-Saharan African. The region fish imports in 2030 are projected to be 11 times higher than the level in 2000. With this prospect, the region's dependency on fish imports is expected to rise from 14 percent in 2000 to 34 percent in 2030.

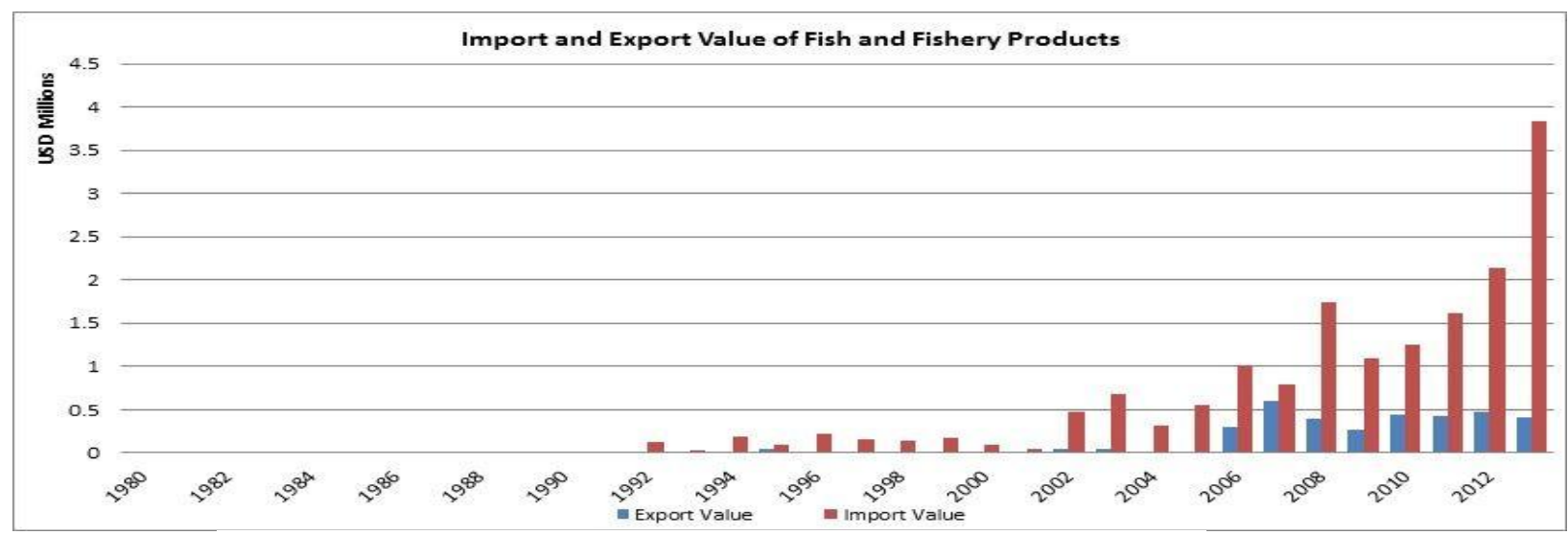

Figure 1:-Ethiopia- Import and export value of fish and fishery products $(\overline{\mathrm{FAO}}, 2014)$

FAO (2012) reports as per capita fish consumption declining in some Sub-Saharan African nations during the 2000s, but World Bank. (2013) projected report shows as fish consumption in Sub-Saharan Africa is stagnant. The reported fish food consumption in Africa in 2009 was 9.1 kilograms per capita per year (FAO, 2012). Whether this will grow in the future with affordable, aquaculture-sourced fish supply, it will not have any contribution for food supply, poverty alleviation and it can also 1 intensifying an important research questions in the region. Generally, to change this condition and boost production of fish, aquaculture remains the most feasible option that can sustain adequate fish food supply in Africa.

Aquaculture practice was officially started in Ethiopia after establishment of the former Sebeta Fish Culture Station (the current National Fishery and Aquatic Life Research Center) in 1977 by then Ministry of Agriculture through financial support obtained from the Government of Japan, Japan International Cooperation Agency. Introduction of Cypernid species (Common carp, Grass carp and Gold fish) from Japan in the late 1970's and culturing of indigenous Tilapia at the center for stocking manmade and some natural water bodies. Since then the center stocked over 8 million fish fingerlings mainly Nile tilapia, Tilapia zilli and common carp mainly to develop extensive aquaculture system in the country (Wakjira et al., 2013; Lakew et al., 2016).

In Ethiopia aquaculture has been proposed by the government of Ethiopia as an option to boost fish production and as an alternative means to food security and poverty alleviation. Nowadays it is considered as an integral part of rural and agricultural development policies and strategies. It was started in the form of extensive aquaculture (Lakew 
et al., 2016). Mainly it was in the form of stocking and enhancing artificial lakes, reservoirs and small water bodies. In the early 2000's, over 2.5 million fingerlings, primarily consisting of Nile Tilapia (Oreochromis niloticus), Tilapia zilli, Common Carp (Cyprinus carpio) and Crucian Carp (Carassius carassius), were stocked (FAO, 2014 ; Lakew et al., 2016).

Nowadays, culture based fisheries is a dominant type of aquaculture practice in Ethiopia. It involves the stocking of newly constructed reservoirs with fingerlings collected from existing water bodies, mostly with tilapia. This consists of extensive aquaculture operations in several small rural-based fish pond sized between 100 and $300 \mathrm{~m}^{2}$. Fish culture cages and pens have not begun yet. Semi-industrial aquaculture practices are at an infant stage of development. Candidate species for aquaculture include Tilapias (Oreochromis niloticus) and the African Catfish (Clarias spp) whilst the aquaculture capabilities of several other species present in fresh water rivers and reservoirs are yet to be explored (FAO, 2009; Kurien et al., 2013; Breuil and Grima, 2014; Lakew et al., 2016).

The production of aquaculture in Ethiopia has not really taken off, and is rather a potential than an actual practice. Even accurate data on production volumes are not documented. However, according to Yalew et al. (2015) estimates, production has increased from 15 to 25 tonnes annually. Currently, the fish feeding habit of the people of Ethiopia was increased especially in and around rift valley system and areas where artificial lakes constricted for other purpose. So practicing of aquaculture up to feasible level is required to feed the ever increasing and adapting fish eating population of this country.

Nowadays, the Ethiopian government has identified aquaculture as one of the strategic areas of intervention to address the problem of food insecurity and poverty in the rural areas. It is considered as an important economic activity that supports diversification, integration and improvement in rural livelihoods (FAO, 2009). Recently, the Ethiopia government re-emphasised on the significance of fish culture at regional and national level and rearing of fingerlings and stocking to water bodies. This can be achieved by rearing of fingerlings at hatchery, preparing ponds for farmers, integrating with terrestrial farming, distribute the fingerlings and support the producers and farmers with continues follow up. With this base line, the principal objective of this review was; to assess aquaculture potential, status, constraints and future prospects in Ethiopia.

\section{Literature Review}

Aquaculture potential in Ethiopia

A potential for aquaculture production in Ethiopia exists, but it is not yet fully realized. Aquaculture in Ethiopia is still in its infancy despite favorable physical conditions available in the country and fish species documented. The high central plateau above 2,500 $\mathrm{m}$ (11 percent of total area) has potential for all year round farming of cold water species. Likewise, the surrounding and central highlands present temperature characteristics favorable for the breeding of a large number of species, from cold water to warm water fish (Breuil and Grima, 2014; Lakew et al., 2016; Natea et al., 2017).

In addition Ethiopia is endowed with 12 drainage basins ( 8 river basin, 1 lake basin and 3 dry basins) with a mean annual flow (runoff) estimated at 122 billion cubic meter and a total length estimated at $8065 \mathrm{~km}$. Similarly, the country has also many lakes and reservoirs, small water bodies and floodplain areas covering a total surface area of about 13,637 km² (Gashaw and Wolff, 2014). The reservoirs under construction such as Gilgel-gibe III and Grand Ethiopian renaissance dam (GERD) will undoubtedly increase the total inland water by over fifteen percent at the end of their completion (Lakew et al., 2016; Meko et al., 2017).

In the same way Ethiopia has very diverse agro-ecological zones offering a favorable potential for developing fish culture both in terms of land/water and in its climatic system. Based on physical, socioeconomic, climatic and infrastructure suitability indicators, as well as the biology of the selected fish species, a GIS analysis was carried out. According to the FAO Sub regional Office for Eastern Africa (FAO SFE) report shows (Rothuis et al., 2012), based on GIS assisted modelling, about $15158 \mathrm{~km}^{2}$ and $871731 \mathrm{~km}^{2}$ of the total country's land, respectively, is highly and moderately suitable for Nile tilapia pond culture. Nevertheless this is equivalent only to about $1 \%$ of the country's surface area, it has been indicated to be sufficient enough to produce significant amount of fish in pond aquaculture (Wakjira et al., 2013). 
On the other hand as the report of Habtesilassie (2012) shows the country has nearly 200 freshwater fish species in its lakes and rivers. However candidate species for aquaculture development in Ethiopia include mainly only Nile tilapia (Oreochromis niloticus) and few the African catfish (Clarias gariepinus) (Yalew et al., 2015).

In spite of some ecological problems reported by conservationists, there have been success stories which resulted in a significant increase in supply of fish for the local communities and markets of major cities. As the evidence from Lakes like: Fincha, Hashenge, Koka, Batu, Gilgal gibe I, Bishoftu, Abaya and others the fish production were inadequate (FAO, 2005; Asaminew, 2012). Nevertheless, the fish productions from these water bodies are supporting the livelihood of poor farmers living around water bodies in providing inexpensive, but high quality protein and promoting income generation. Generally aquaculture in Ethiopia remains more potential than in actual practice, despite the fact that the country's environmental and socio-economic conditions support its development (Natea et al., 2017; Asmare, 2017).

\section{Status of Aquaculture in Ethiopia}

Ethiopia is endowed with considerable amounts of freshwater systems including lakes, reservoirs, rivers, ponds and wetlands that support development of aquaculture sector. The nation's freshwater system sustain considerable amount of fisheries that have significant nutritional and economic values. However, the capture fisheries are unregulated and poorly managed leading to resource overexploitation, degradation of biological diversity and reduction in fish supplies and income (MoA, 2011; Natea et al., 2017). Despite of having favorable physical and hydrographic conditions (suitable geographic relief, rich soil quality, good mean annual rainfall, and sufficient freshwater availability), the aquaculture production is negligible in Ethiopia. Eventhough the country has high potential and wide environmental condition for aquaculture farming; it was existing as small-scale, subsistenceoriented and only to a certain degree commercial. It is estimated that there are more than 1300 subsistence fish farmers in Ethiopia with a pond size of about $100-300 \mathrm{~m}^{2}$ (Abera, 2017).

The consumption and demand for fish as a cheap source of protein is increasing in Ethiopia. But the fish supply in most cases comes from the major lakes and rivers in the country. While capture fisheries based on species that are presently exploited seem to have reached their natural limits (MoA, 2011; Asaminew, 2012). As a result of high population growth in the country, there is high competition to be engaged in fisheries activities around the lakes area. Thus, as the experience of different countries in the world shows, if aquaculture is developed in a sustainable way, it can be the best alternative to tackle this kind of problems

According to FAO estimates, per capita fish consumption in Ethiopia at 2009 was estimated to $0.2 \mathrm{~kg}$, which places the country in the lower end of fish consumers amongst African countries (where the average is $9.4 \mathrm{~kg}$ ). National estimates for 2012 indicate a higher yearly per capita consumption at $0.34 \mathrm{~kg}$. This national average does not reflect regional differences in consumption. In areas surrounding lakes and rivers, yearly consumption can reach $21 \mathrm{~kg}$ per capita (John and Rios, 2013). Domestic supply is fulfilled entirely by capture fisheries and fishery resources are assessed as underexploited overall. Fisheries contribute to food security in Ethiopia at a very low level. In 2009, FAO estimated that fishery products account for 1 percent of animal protein intake, were below the African average (19.1 percent). Ethiopia is a country where animal protein from fish is the lowest in Africa. The per capita protein supply from fish has shown an inconsistent performance, reaching 0.1 grams in 2009 (Breuil and Grima, 2014; FAO, 2014). 


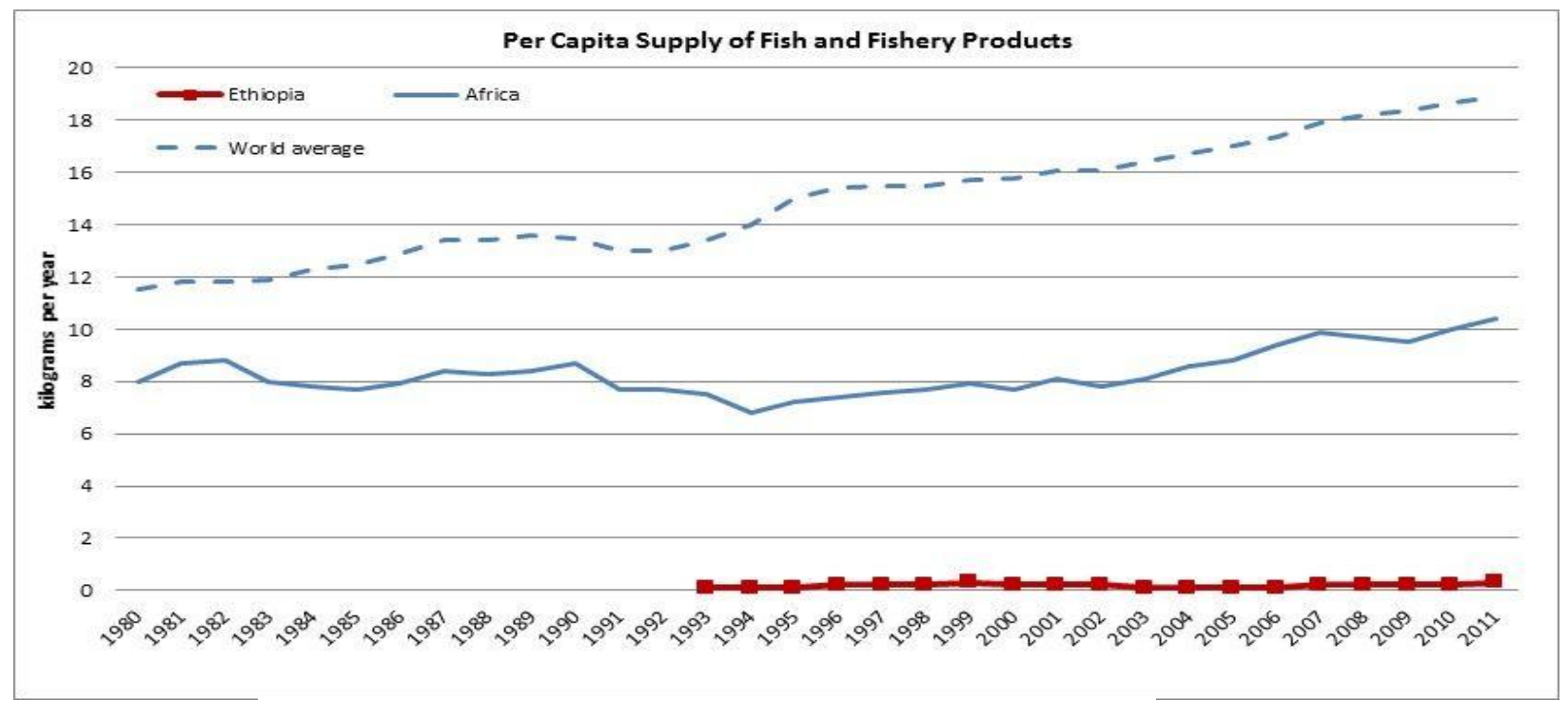

Figure 2:-Ethiopian-per capita supply of fish and fishery products $(\overline{\mathrm{FAO}}, 2014)$

Commercial hatcheries are non-existent. Mono-sex Nile tilapia fingerlings are neither readily available, nor African catfish fingerlings. Only a few government and private farms that could supply tilapia fingerlings from pond nurseries exist in the country(Lakew et al., 2016; Natea et al., 2017). Therefore, the supply of fingerlings should be ensured either through establishment of artificial hatchery or via sustainable pond hatchery systems.

Aquaculture activities in Ethiopia have been limited to introduction of both exotic and indigenous freshwater fish to several man-made and natural water bodies (Asaminew, 2012; Lakew et al., 2016). In most cases Nile tilapia (Oreochromis niloticus L.) has been stocked to several small water bodies, because of its adaptability to wide environmental conditions as well as the high demand of the fish by the local consumer (Lakew et al., 2016; Natea $e t$ $a l .$, 2017). Eventhough there were different types of fish species in Ethiopia mainly dependence on Nile tilapia was seen. That is Nile tilapia is benchmark of the country fish farm production hence, narrowing Ethiopian production diversity of aquaculture. Eventhough, African catfish has great economic importance next to Nile tilapia in the country fisheries product, yet its farming is not well practiced. Fortunately, African catfish farming has witnessed an increased production of aquaculture in Ethiopia (Natea et al., 2017).

Aquaculture has a great potential in the struggle for improvement of the nutritional situation of the human population and in the alleviation of poverty of rural people of the country (Natea et al., 2017). The demand for fish has been on the increase in the last decade; as a result most of the Ethiopian lakes are over exploited.

Several national reports indicate that fisheries production of the major lakes of Ethiopia is declining in an alarming rate (MoA, 2011; Wakjira et al., 2013; Natea et al., 2017). The fisheries for some of the lakes have already reached the level of none rewarding to the fishermen due to very small size of the catch. The production of small sized fish (Nile perch in Lakes Abaya and Chamo and Nile tilapia in Lake Ziway) probably lead to extinction of species in these lakes as the result of pre-mature harvesting. In Ethiopia, fisheries from natural water bodies have failed to meet the ever growing demand for fish (Asaminew, 2012; Wakjira et al., 2013). Moreover, as a result of high population growth in the country there is high competition to be engaged in fisheries activities around the lake region. Thus, as the experience of different countries in the world shows, if aquaculture developed in a sustainable way, it is the best alternative to tackle this kind of problems (Watanabe, 2002; Yang et al., 2006; Natea et al., 2017). Therefore countries like Ethiopia, where there is sever food shortage, the country can utilize the diverse resources in a sustainable way. Despite the countries huge aquaculture potential, the contribution of aquaculture towards food security is insignificant (MoA, 2011). Hence, the importance of aquaculture development for poverty mitigation and food self-sufficiency in the country should get attention. Although national data on various aspects of aquaculture including total production is not well studied, not well organized and lack accessibility. According to the FAO Fisheries statistics the country's aquaculture production is insignificant when compared with the production coming from its capture fisheries (FAO, 2018). 
In general, aquaculture in Ethiopia is at a very low level of development due to lack of extension support and training, shortage of expertise, lack of fingerlings, lack of funding, little research and institutional capacity. Nowadays there are certain trials to increase fish production and to integrat aquatic farming with terrestrial farmiarng at different parts of the country by the Sebeta Fisheries and Aquatic Life Research Center, Batu Fishery Research Center and Bahirdar Fisheries and other Aquatic Life Research Center for the farmers. Moreover the started trials on the artificial propagation of fingerlings at these centers must be supported and supplemented by necessary inputs. To boom and assure this practice the farmers should be trained by the expertis come from those institutions before the start of fish farming.

\section{Constraints and future prospects of aquaculture in Ethiopia Constraints}

Basically aquaculture needs certain resources and inputs such as fish seeds, pond, fish feeds and fishing gears. Global aquaculture is now the fastest growing food production sub-sector in many countries and it is expected that this trend will continue despite several constraints, which may become more challenging in the future (FAO, 2014; FAO, 2018). Including Ethiopia in many developing countries there is significant scope for enhancing contributions of aquaculture to food supplies and poverty alleviation. However, in Ethiopia fingerlings required for stocking new ponds and reservoirs have traditionally been obtained from the natural lakes (Natea et al., 2017).

The aquaculture development in Ethiopia was faced with a number of challenges which include mainly; lack of cheap and efficient locally available fish feeds, lack of locally selected and certified fish seeds. Likewise, the problem of land ownership policies in the country, over-reliance on capture fisheries, not have successful integration of aquaculture with other farming activities, shortage of small-scale low-cost aquaculture support for rural development, lack of licensed fish seed multiplication centers and lack of institutional capacity in the area of training, research and technology transfer also challenging conditions for aquaculture development in Ethiopia. In addition to those challenging conditions scarcity of trained manpower and lack of government attention are also not easy confines for aquaculture development in the country (Tilahun et al., 2016; Natea et al., 2017; Meko et al., 2017).

Moreover, hatchery rearing for the development of fish farming, especially among smallholder farmers to larger producers is not known yet. To make aquaculture more effective, hatchery rearing and cheap fish feed can play an important role to solve the fingerling scarcity at a time of demand and to intensifying aquaculture sector in Ethiopia (Lakew et al., 2016; Abera, 2017; Natea et al., 2017; Asmare, 2017; AFD, COM and GIZ, 2017).

\section{Future prospects}

The country has launched a number of projects aiming at increasing the national economy and improving the livelihood of its people. As explicitly indicated in the GTP plan large sized reservoirs and dams were going to be constructed primarily aiming at generating electricity. Others are dammed to store water for the purpose of irrigation based agriculture. These water bodies can be used to integrate cultured based fishery and enhance the fishery production nationwide. Some success stories includes the production of fish from reservoirs of Koka, Fincha, Gilgelgibe I, Melkawakena and Tendaho were reported. On the other hand along with the newly established sugar cane factories and small to medium scale irrigation facilities, more reservoirs will be used for fish production without affecting their primary purpose. The grand renaissance dam on Abay(Nile) river and other hydrodams in Omo-Gibe and Genale basins are soon coming with high fish production areas in the country. This technology requires fish seed multiplication, fish feed and transportation facilities to stock such big water bodies. Therefore, prior preparedness will be required by the concerned ministries and institutions for sufficient delivery and stocking of the water bodies by suitable fish species (Lakew et al., 2016; Abera, 2017; Meko et al., 2017).

So that to transform the rate of aquaculture development in Ethiopia, the country will need a multi-sectoral approach and well-coordinated collaborative efforts from all different stakeholders. Therefore a major future task is to increase participation of producers and relevant public authorities in the allocation and management of aquatic resources and land uses. The continues capacity building through Universities in graduating trained human power, provision of training, extension, and advanced education to fish producers by respective research centers were crucial for successful development of the aquaculture sector in Ethiopia (Yalew et al., 2015; Abera, 2017). 


\section{Conclusion:-}

Ethiopia was endowed of humble natural resources (aquatic resources), but the benefit from these resources were negligible. Like most of Africa countries, Ethiopia is riddled with poverty, economic stagnation and environmentally unsustainable practices, all of which pose serious constraints on fisheries development. In Ethiopia despite, the fact that the country's environmental and socio-economic conditions support aquaculture development, it remained more potential than in actual practice. This mean, in the contrary there was a huge aquaculture potential, but Ethiopia didn't harvest adequate products from this sector. In the country Ethiopia aquaculture has been proposed by the government as an option to boost fish production and as an alternative means for food security, poverty alleviation, economic growth, better nutrition and ecological improvement. So to enhance and to produce the required product from aquaculture sector, the Ethiopian government must make avail basic infrastructure and equipment, restore the degraded natural resources and allocate sufficient funds to implement the country's strategies, plans and legislations on the aquaculture sector.

Generally, to realize and make sustainable the aquaculture production: the improvement in fishing techniques, technology transfer to fishers, training of fishery management personnel, attraction of financial capital to the industry and fish value chain improvement, must get emphasis by the government. The combination of those efforts can all result to increased fish production and overall economic development of the country. Therefore aquaculture contributes to the livelihoods of the poor society through improved food supply, employment, and income generation. In the same way, it can also provide a viable socio-economic alternative to capture fisheries. Or this mean aquaculture is carried out not only for increasing the availability of fish for food but also to conserve the natural stock and thereby protect the biodiversity.

\section{Acknowledgement}

The author would like to express his gratitude to the Department of Biology, College of Natural Sciences, Jimma University for material support. He would further express his appreciation to Prof. Adiveppa Kadi for his cooperation for the publication processes of this review.

\section{References:-}

1. Abera, L.(2017). Fisheries production system scenario in Ethiopia. Int. J of Fisheries and Aquatic Studies. 5(1): 79-84.

2. Agence Française de Développement (AFD)., European Commission (COM) and Gesellschaft für Internationale Zusammenarbeit (GIZ). (2017). Opportunities and challenges for aquaculture in developing countries. Joint Report.

3. Asaminew, K. (2012). Utilization of locally available feedstuffs for small-scale aquaculture production in Ethiopia. Doctoral Dissertation at University of Natural resources and Applied life Sciences, Vienna, Austria.

4. Asmare, E. (2017). Financial Viability of Hatchery Rearing of Oreochromis niloticus at Dera District, Amhara Region, Ethiopia. J Fish Aqua Development.

5. Breuil, Chr. and Grima, D. (2014). Baseline Report Ethiopia. Smart Fish Programme of the Indian Ocean Commission, Fisheries Management FAO component, Ebene, Mauritius. 24 pp.

6. FAO.(2009). National Aquaculture Development Strategy of Ethiopia. Addis Ababa. FAO.33 pp.

7. FAO. (1996). Aquaculture production statistics 1984-94. FAO fisheries Circular, No 815, Revision.

8. FAO. (2005). Ethiopia information on fisheries management (from IFMC) water report no. 29, FAO, Rome, Italy.

9. FAO. (2002). Global Aquaculture Production. Fishery Statistical Collections. FAO Fisheries and Aquaculture Department, Rome

10. FAO, Rome, Italy FAO. (2006). State of world aquaculture 2006. FAO Fisheries Technical Paper 500, Rome, Italy.

11. FAO. (2012). Brief on fisheries and aquaculture in Ethiopia.

12. FAO.(2014). Fishery and Aquaculture Country Profles: The Federal Democratic Republic of Ethiopia. FAO Fisheries and Aquaculture Department. Rome.

13. FAO.(2018). The State of World Fisheries and Aquaculture. Meeting the sustainable development goals. Rome.

14. Gashaw, T. and Wolff, M. (2014). The state of inland fisheries in Ethiopia: a synopsis with updated estimates of portential yield. Ecohydrology and Hydrobiology. 14:200-219. 
15. Habtesilassie, R. (2012). Fishes of Ethiopia: annotated checklist with pictorial identification guide. p.250. Office for Development Cooperation of Austrian Embassy, Addis Ababa, Ethiopia

16. John, K. and Rios, L. (2013). Fisheries and Food Security in the ESA-IO Region. Ethiopia Country Brief. IOC-Smart Fish Programme. FAO.

17. Lakew, A., Tadesse, Z. and Dagne, A. (2016). Technologies Suitable for Aquaculture Development in Ethiopia. Ethiopia Fish and fisheries Association.

18. Meko, T., Kebede. A., Hussein, A. and Tamiru, Y. (2017). Review on Opportunities and Constraints of Fishery in Ethiopia. Fish Sci .1(1):1-8.

19. Ministry of Agriculture (MoA). (2011). Annual report.

20. Natea, G., Wakjira, M., Negisho, T. and Endebu, M. (2017). Spawning response of African catfish (Clarias gariepinus (Burchell 1822), Claridae: Teleost) exposed to different piscine pituitary and synthetic hormone. Inte. J of Fisheries and Aquatic Studies. 5(2): 264-269.

21. Tilahun, A., Alambo, A. and Getachew, A. (2016). Review on Fish Production Constraints in Ethiopia. World $J$ of Fish and Marine Sciences. 8 (3): 158-163.

22. Wakjira, M., Tolemariam, T., Kim, J. D. and Kim, K. R. (2013). Aquaculture Development in Ethiopia: Review on Potential and Strategy. J of Agricultural, Life and Environmental Sciences. 25(3):20-25.

23. Watanabe, T. (2002). Strategies for further development of aquatic feeds. Fisheries Science. 68: 242-252.

24. World Bank. (2013). Agriculture and Environmental Services Discussion Paper. FISH TO 2030 Prospects for Fisheries and Aquaculture. WORLD BANK REPORT NUMBER 83177-GLB Public Disclosure Authorized.

25. Yalew, A., Dejen, E. and Spliethoff, P. (2015). Business Opportunities Report Aquaculture \#10 in the series written for the "Ethiopian Netherlands business event. Rijswijk, The Netherlands.

26. Yang, Y., Xie, S., Cui, Y., Zhu, X. and Lei, W. (2006) . Partial and total replacement of fishmeal with poultry by-products meal in diets of gibel carp, Carassius auratus gibelio Blouch. Aquaculture research. 37:40-48. 